\title{
Antibiotic Susceptibility Patterns of Aggregatibacter actinomycetemcomitans and Porphyromonas gingivalis Strains from Different Decades
}

\author{
Eva M. Kulik ${ }^{1, *}$, Thomas Thurnheer ${ }^{2}{ }^{\oplus}$, Lamprini Karygianni ${ }^{2}{ }^{\oplus}$, Clemens Walter $^{3}$, \\ Anton Sculean ${ }^{4}$ and Sigrun Eick ${ }^{4}$ \\ 1 Department of Oral Health \& Medicine, University Center for Dental Medicine, University of Basel, \\ 4058 Basel, Switzerland \\ 2 Clinic of Conservative and Preventive Dentistry, Division of Oral Microbiology and Immunology, Center of \\ Dental Medicine, University of Zurich, 8032 Zurich, Switzerland; thomas.thurnheer@zzm.uzh.ch (T.T.); \\ lamprini.karygianni@zzm.uzh.ch (L.K.) \\ 3 Department. of Periodontology, Endodontology and Cariology, University Center for Dental Medicine, \\ University of Basel, 4058 Basel, Switzerland; clemens.walter@unibas.ch \\ 4 Department of Periodontology, School of Dental Medicine, University of Bern, 3001 Bern, Switzerland; \\ anton.sculean@zmk.unibe.ch (A.S.); sigrun.eick@zmk.unibe.ch (S.E.) \\ * Correspondence: eva.kulik@unibas.ch
}

Received: 31 October 2019; Accepted: 2 December 2019; Published: 6 December 2019

\begin{abstract}
The aim of this study was to determine the antibiotic susceptibility patterns of 57 Aggregatibacter actinomycetemcomitans and 56 Porphyromonas gingivalis strains isolated from subgingival biofilm samples of periodontitis patients in Switzerland from 1980 to 2017. The minimal inhibitory concentrations (MIC) of the most commonly used antibiotics in periodontal therapy (amoxicillin, metronidazole, azithromycin, and doxycycline) or in severe body infections (amoxicillin/clavulanic acid, clindamycin, ertapenem, and moxifloxacin) were determined. Furthermore, all the strains were screened for beta-lactamase activity and the presence of selected resistance genes $(c f x \mathrm{~A}, \operatorname{erm} \mathrm{F}$, and tet $\mathrm{Q})$. Overall, there was no significant increase in MIC values over the 37-year period. Two of the most recent $P$. gingivalis isolates yielded the highest MIC values. The first isolate was ermF-positive with MIC values $>8 \mu \mathrm{g} / \mathrm{mL}, 2 \mu \mathrm{g} / \mathrm{mL}$, and $0.25 \mu \mathrm{g} / \mathrm{mL}$ for clindamycin, azithromycin, and moxifloxacin, respectively. The second isolate showed a high MIC value of $4 \mu \mathrm{g} / \mathrm{mL}$ for moxifloxacin, which was associated with a confirmed single-point mutation in the quinolone resistance-determining region (QRDR) of the gyrA gene. Although there was no significant increase in the antibiotic resistance among the oral bacterial isolates tested, the detection of resistant $P$. gingivalis isolates underlines the need to optimize the antibiotic therapeutic protocols in dentistry.
\end{abstract}

Keywords: minimal inhibitory concentrations; periodontal pathogens; beta lactams; moxifloxacin

\section{Introduction}

Due to increased and often unrestricted consumption of antibiotics both in humans and in animal husbandry, the development of resistance against antibiotics has become a global healthcare threat leading to higher medical costs, prolonged hospital stays, and increased mortality [1,2]. There is an urgent need for change in the prescription and use of antibiotics [3,4]; however, so far, strategies based on antibiotic stewardships, infection prevention and control programs were unable to control the increase in antimicrobial resistance [5]. As there is also a lack of new antimicrobials that are effective against resistant bacteria, the knowledge of factors contributing to the spread of resistant microorganisms is of high importance [6]. 
A recent analysis in the U.S showed that dentists account for $13.2 \%$ of all antibiotic prescriptions among the antibiotic prescriptions providers, with periodontists having a higher prescription rate than general dentists [7]. Periodontal diseases are polymicrobial oral infections by predominantly Gram-negative capnophilic and anaerobic subgingival bacterial species such as Aggregatibacter actinomycetemcomitans and Porphyromonas gingivalis [8]. The virulence factors of $A$. actinomycetemcomitans, associated with severe periodontitis in young age, include leukotoxin, cytolethal distending toxin, and lipopolysaccharide [9]. P. gingivalis has high proteolytic activity and is considered a keystone pathogen in the initiation and progression of periodontal disease [10]. Besides the mechanical debridement of infected periodontal pockets, clinical treatment protocols for severe forms of periodontitis often involve the adjunctive use of antibiotics like amoxicillin, metronidazole, azithromycin, and tetracycline [11,12].

The objective of this study was to determine the antibiotic susceptibility among clinical isolates of A. actinomycetemcomitans and P. gingivalis isolated from Swiss periodontitis patients over four decades.

\section{Results}

In total, 57 A. actinomycetemcomitans and 56 P. gingivalis strains could be included in this study. Only one isolate per patient was considered in the analysis. As $P$. gingivalis strains were only available from 1990 on, isolates were not equally distributed over the different decades (Table 1).

Table 1. Temporal distribution of A. actinomycetemcomitans and P. gingivalis isolates.

\begin{tabular}{ccc}
\hline Years & A. actinomycetemcomitans & P.gingivalis \\
\hline $1980-1989$ & 22 & $n a$ \\
$1990-1999$ & 19 & 25 \\
$2000-2009$ & 8 & 11 \\
$2010-2017$ & 8 & 20 \\
\hline
\end{tabular}

na: no isolates available.

Table 2 shows the $\mathrm{MIC}_{50}$ and $\mathrm{MIC}_{90}$ values for the tested antimicrobials. The results confirm the high resistance of $A$. actinomycetemcomitans against clindamycin $(\geq 8 \mu \mathrm{g} / \mathrm{mL})$ and metronidazole $\left(\geq 32 \mu \mathrm{g} / \mathrm{mL}\right.$ ). The $\mathrm{MIC}_{90}$ values for ampicillin and amoxicillin/clavulanic acid were $2 \mu \mathrm{g} / \mathrm{mL}$ and $2 / 1 \mu \mathrm{g} / \mathrm{mL}$, respectively, whereas the $\mathrm{MIC}_{50}$ and $\mathrm{MIC}_{90}$ values of the other antimicrobials were low. P. gingivalis yielded low $\mathrm{MIC}_{50}(0.0625-0.5 \mu \mathrm{g} / \mathrm{mL})$ and $\mathrm{MIC}_{90}(0.125-2 \mu \mathrm{g} / \mathrm{mL})$ values for all the antimicrobials tested.

Table 2. $\mathrm{MIC}_{50}$ and $\mathrm{MIC}_{90}$ values $(\mu \mathrm{g} / \mathrm{mL})$ for A. actinomycetemcomitans and P. gingivalis strains.

\begin{tabular}{ccccc}
\hline Antibiotic & \multicolumn{3}{c}{$\begin{array}{c}\text { A. } \\
\text { actinomycetemcomitans }\end{array}$} & P.gingivalis \\
& MIC50 & MIC90 & MIC50 & MIC90 \\
\hline Ampicillin & 0.5 & 2 & 0.125 & 0.5 \\
Amoxicillin/Clavulanic Acid & $0.5 / 0.25$ & $2 / 1$ & $0.5 / 0.25$ & $0.5 / 0.25$ \\
Clindamycin & 8 & $>8$ & 0.0625 & 0.25 \\
Azithromycin & 0.25 & 1 & 0.250 & 0.5 \\
Ertapenem & 0.125 & 0.25 & 0.125 & 0.25 \\
Doxycycline & 0.5 & 1 & 0.25 & 1 \\
Moxifloxacin & 0.0625 & 0.125 & 0.0625 & 0.125 \\
Metronidazole & 32 & $>32$ & 0.25 & 2 \\
\hline
\end{tabular}

The susceptibility of A. actinomycetemcomitans (Figure 1) and P. gingivalis (Figure 2) to most of the antimicrobials did not change over time. A. actinomycetemcomitans showed statistically significant differences for azithromycin $(p=0.002)$ and clindamycin $(p=0.004)$. In particular, azithromycin exhibited the highest cumulative MIC values in the first decade (1980-1989), while clindamycin 
yielded the lowest cumulative MIC values in the last decade (2010-2017). Regarding $P$. gingivalis, statistically significant differences were observed for clindamycin $(p=0.006)$, ertapenem $(p=0.014)$, and doxycycline $(p=0.040)$.

The $c f x \mathrm{~A}$ gene was not detected in any of the tested P. gingivalis and A. actinomycetemcomitans strains and the nitrocefin test was negative for all tested isolates. The tet $\mathrm{Q}$ gene was identified in two P. gingivalis strains, one of which yielded a MIC of $1 \mu \mathrm{g} / \mathrm{mL}$ for doxycycline.

Two P. gingivalis strains isolated in the last decade (2010-2017) showed the highest MIC values. One isolate was ermF-positive and had MIC values higher than $8 \mu \mathrm{g} / \mathrm{mL}, 2 \mu \mathrm{g} / \mathrm{mL}$, and $0.25 \mu \mathrm{g} / \mathrm{mL}$ for clindamycin, azithromycin, and moxifloxacin, respectively. The second isolate had a high MIC value of $4 \mu \mathrm{g} / \mathrm{mL}$ for moxifloxacin. Sequence analysis of the quinolone resistance-determining region (QRDR) of the gyrA gene confirmed a gene mutation, namely a Ser-83 $\geq$ Phe substitution [13].
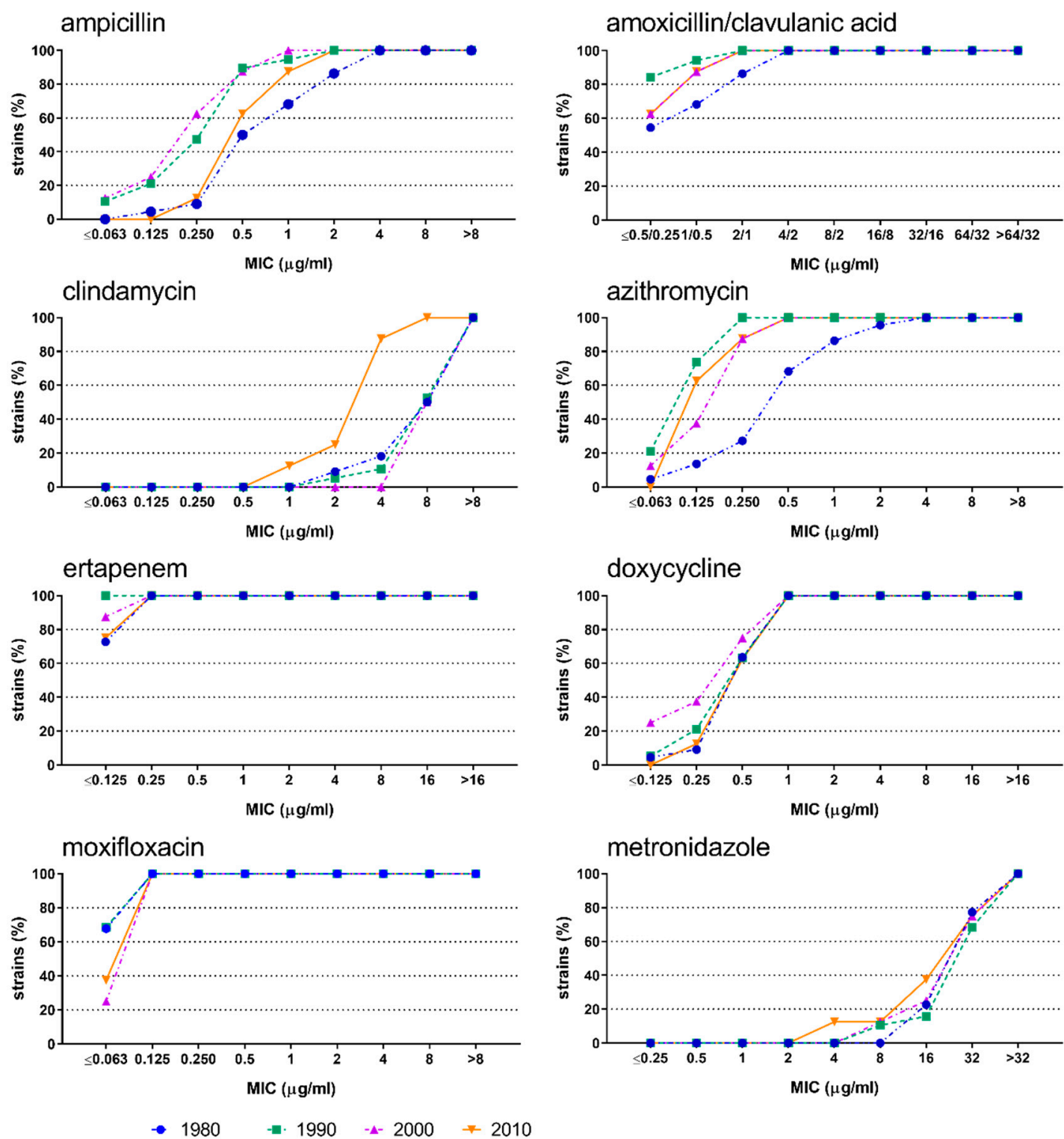

Figure 1. Cumulative minimal inhibitory concentrations against Aggregatibacter actinomycetemcomitans isolates. Results are shown for the antibiotics ampicillin, amoxicillin/clavulanic acid, clindamycin, azithromycin, ertapenem, doxycycline, moxifloxacin, and metronidazole during the decades 1980 (1980-1988; blue), 1990 (1990-1999; green), 2000 (2000-2009; purple), and 2010 (2010-2017; orange). 

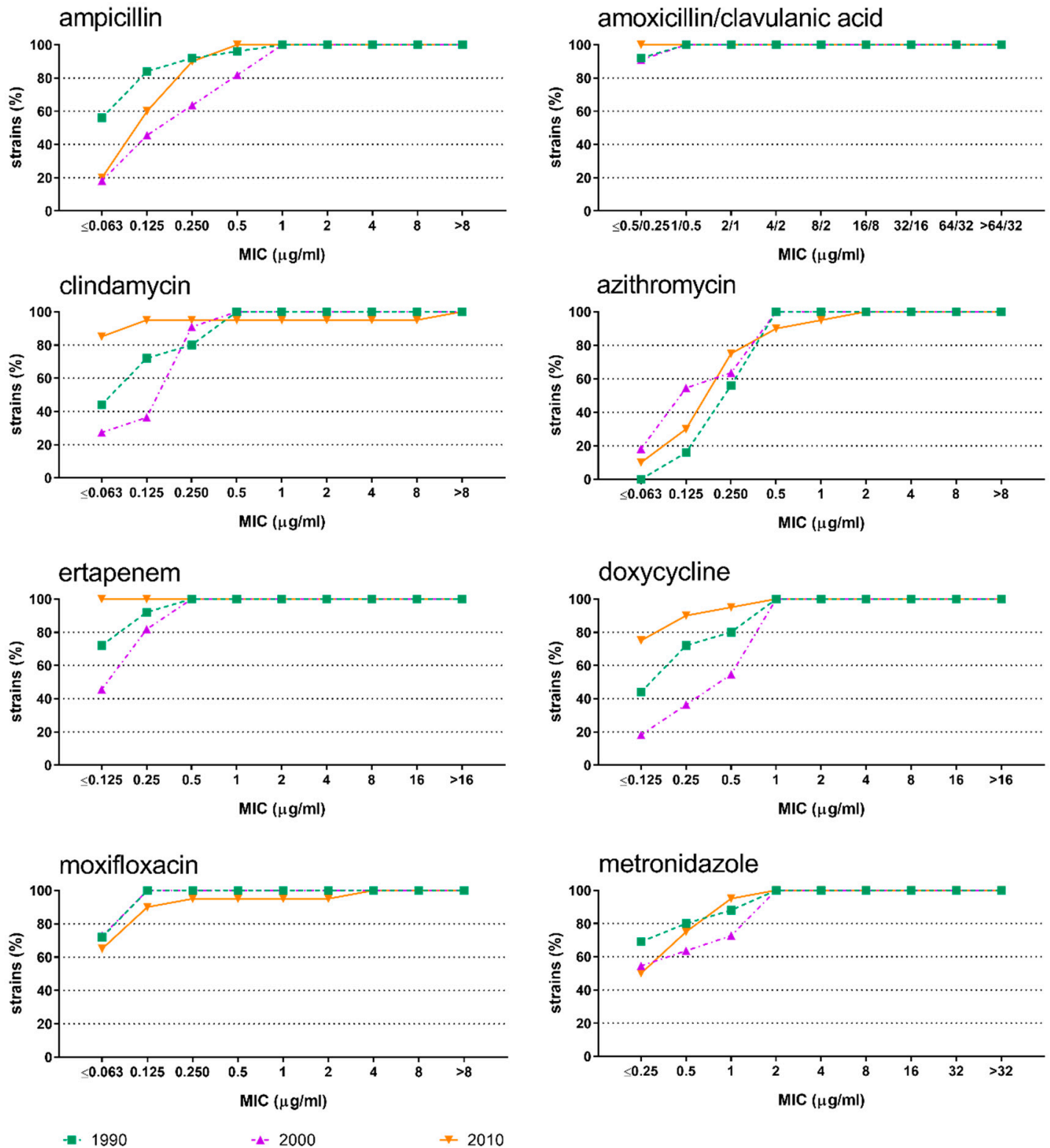

Figure 2. Cumulative minimal inhibitory concentrations against Porphyromonas gingivalis isolates. Results are shown for the antibiotics ampicillin, amoxicillin/clavulanic acid, clindamycin, azithromycin, ertapenem, doxycycline, moxifloxacin, and metronidazole during the decades 1990 (1990-1999; green), 2000 (2000-2009; purple), and 2010 (2010-2017; orange).

\section{Discussion}

Overall, an increase of MIC values among the tested A. actinomycetemcomitans and $P$. gingivalis isolates over the 37-year period could not be observed. Although only a limited number of clinical isolates was analyzed in this study, the results are in agreement with a previous Swiss study, where no increase was detected in antibiotic-resistant oral bacteria after comparing Prevotella intermedia and A. actinomycetemcomitans strains isolated during 1991-1994 with isolates collected during 2001-2004 [14]. The absence of an increasing antibiotic resistance among the tested bacteria associated with periodontal disease over the last 37 years might be attributed to the restricted use of antibiotics in the treatment of severe forms of chronic periodontitis at the dental university clinics of Basel, Bern, and Zurich. A questionnaire among dentists in dental practices in Switzerland confirmed that the prescription of 
antibiotics in Switzerland is selective and cautious [15]. In contrast, many prescriptions in the United States are considered to involve 'inappropriate' use of antibiotics [16].

In regard to the resistance profiles of A. actinomycetemcomitans and $P$. gingivalis, our results are comparable to data from the Netherlands [17]. Similarly, a high sensitivity of $P$. gingivalis to antibiotics commonly used in dentistry is found in the United States and Norway, whereas a significant amount of A. actinomycetemcomitans strains is resistant to tetracycline $[18,19]$. Antibiotic resistances of other oral anaerobic bacteria are of increasing clinical importance as well. In particular, oral Prevotella spp. isolated from periodontal abscesses were resistant to metronidazole (9.5\%), amoxicillin (30.9\%), clindamycin $(38.1 \%)$, and doxycycline (4.8\%). Their increased resistance was often related to the presence of nim, cfxA, ermF, and tet $\mathrm{Q}$ genes [20]. In another study, oral isolates of P. intermedia and Prevotella buccae yielded high MIC values for doxycycline and tetracycline [21]. In our study, the ermF gene was identified in accordance with a phenotypical resistance to clindamycin only in one P. gingivalis isolate. The tet $\mathrm{Q}$ gene was present in only one of the two respective $P$. gingivalis isolates associated with a slightly elevated MIC value to doxycycline.

In subgingival plaque, bacteria are organized as a complex biofilm. In general, MIC values are higher for bacteria in biofilms than for planktonic cultures [22]. Various biofilm models exist for analyzing antimicrobial susceptibility and first attempts are being made to determine the antibiotic concentrations that can inhibit all microorganisms present in a polymicrobial sample $[23,24]$.

One of the $P$. gingivalis strains from our study, a strain isolated from a patient with rheumatoid arthritis in the decade 2010-2017, showed an elevated MIC value for the fluoroquinolone, moxifloxacin, which was due to a mutation in the gyrA gene. No resistance to quinolones has been reported in clinical oral isolates of $P$. gingivalis so far. However, moxifloxacin resistance in $P$. gingivalis strains could be induced in vitro by exposing $P$. gingivalis strains to subinhibitory concentrations of fluoroquinolones. In this study, published in 2004, resistance was shown to be due to a Ser-83 $\geq$ Phe substitution in the gyrA gene of the QRDR [13]. At that time, the adjunctive use of moxifloxacin was promoted in periodontal therapy because of the antibiotic's ability to penetrate into tissues and cells of anaerobic periodontal pathogens in both the planktonic as well as biofilm state [22,25].

Meanwhile, due to the increasing development of resistance to quinolones which is associated with the overuse of this antibiotic class, personalized and restricted prescription is considered to be crucial [26]. Interestingly, the $P$. gingivalis isolate with the gyrA mutation was isolated from a patient with rheumatoid arthritis. Since quinolones are rarely used in periodontal therapy in Switzerland, this resistance may be associated with the treatment of non-oral bacteria. Certainly, the detection of quinolone-resistant clinical isolates of $P$. gingivalis should raise concerns about the use of antibiotics in the treatment of bacterial-induced oral infections such as periodontitis. Inappropriate use of antibiotics may not only lead to an increase in adverse events and healthcare costs, but might also contribute to the selection of antibiotic-resistant bacteria.

\section{Materials and Methods}

\subsection{Isolation of Bacteria}

All clinical isolates were obtained from subgingival biofilm samples of Swiss periodontitis patients between 1980 and 2017 and stored at $-80^{\circ} \mathrm{C}$ in the respective strain collections of the oral microbiology diagnostic laboratories in Basel, Bern, and Zurich. The most recent clinical strains originate from two studies approved by the Ethics Committee Bern (\#236/2010 and \#096/2015). The identification of species changed over time; therefore, the species identity of all the strains was confirmed by using specific $16 \mathrm{~S}$ rDNA-real-time PCR analysis [27]. In total, 57 A. actinomycetemcomitans and 56 P. gingivalis strains could be included in the analysis. For resistance testing, these isolates were then cultured on Tryptic Soy agar plates with 5\% sheep blood (Oxoid, Thermo Fisher Diagnostics AG, Pratteln, Switzerland), and incubated anaerobically. 


\subsection{Determination of the Minimal Inhibitory Concentration (MIC) and Resistance Testing}

MICRONAUT-S Anaerobe MIC plates (Merlin Diagnostica, Bornheim-Hersel, Germany) were used for determining the minimal inhibitory concentrations (MICs) for the following antibiotics:ampicillin (range: $0.063-8 \mu \mathrm{g} / \mathrm{mL}$ ), amoxicillin/clavulanic acid (range: 0.5/0.25-64/32 $\mu \mathrm{g} / \mathrm{mL}$ ), clindamycin (range: 0.063-8 $\mu \mathrm{g} / \mathrm{mL}$ ), ertapenem (range: $0.125-16 \mu \mathrm{g} / \mathrm{mL}$ ), doxycycline (range: $0.125-16 \mu \mathrm{g} / \mathrm{mL}$ ), metronidazole (range: $0.25-32 \mu \mathrm{g} / \mathrm{mL}$ ), and moxifloxacin (range: $0.063-8 \mu \mathrm{g} / \mathrm{mL}$ ). The tests were performed according to the manufacturer's recommendations. For azithromycin (range: $0.063-8 \mu \mathrm{g} / \mathrm{mL}$ ), a microbroth dilution assay was used.

Elevated MICs were confirmed by an agar dilution technique using Wilkins Chalgren agar plates with 5\% laked horse blood (Oxoid, Thermo Fisher Diagnostics AG, Pratteln, Switzerland). All the strains were screened for beta-lactamases using nitrocefin discs as described by the manufacturer (Sigma-Aldrich, Buchs, Switzerland). The presence of the $c f x \mathrm{~A}$, ermF, and tetQ genes was determined by real-time PCR assays using GoTaq ${ }^{\circledR}$ qPCR Master Mix (Promega AG, Dübendorf, Switzerland) and specific primers [28]. A strain with an elevated resistance against moxifloxacin was forwarded to PCR analysis of the gyrA quinolone resistant determining region (QRDR) [13] and subsequent sequencing of the PCR product (Microsynth AG, Balgach, Switzerland).

The MIC results were interpreted using EUCAST breakpoints for anaerobic bacteria in the case of $P$. gingivalis. In the case of A. actinomycetemcomitans, the interpretive criteria for the HACEK-group were applied [29]. The distribution of the MIC values is shown by presenting the cumulative MIC values and by calculating the necessary concentrations to inhibit 50\% $\left(\mathrm{MIC}_{50}\right)$ and $90 \%(\mathrm{MIC} 90)$ of the respective strains.

\subsection{Statistical Analysis}

The descriptive analysis and $\mathrm{Chi}^{2}$ test were done using SPSS 24.0 (IBM, Chicago, IL, USA).

\section{Conclusions}

There was no significant increase in the antibiotic resistance among the oral bacterial isolates tested. However, the detection of resistant $P$. gingivalis isolates underlines the need to optimize the antibiotic therapeutic protocols in dentistry.

Author Contributions: Conceptualization, E.M.K., T.T. and S.E.; methodology, E.M.K., T.T. and S.E.; formal analysis, S.E.; validation, E.M.K., T.T. and S.E.; investigation, E.M.K., L.K., S.E.; resources, T.T., C.W., S.E.; data curation, E.M.K., T.T. and S.E.; writing-Original draft preparation, E.M.K., L.K., S.E.; writing-Review and editing, E.M.K., T.T., L.K., C.W., A.S., S.E.

Funding: This research received no external funding.

Acknowledgments: The authors are grateful for the excellent technical assistance by Anna Magdoń, Rita Joanna Bernet, Pauline Scherwey (Bern), and Irene Schweizer (Basel) and for the valuable scientific support of Tuomas Waltimo (Basel), Burkhard Möller (Bern), Thomas Attin (Zurich), and Georgios Belibasakis (Stockholm).

Conflicts of Interest: The authors declare no conflict of interest.

\section{References}

1. Durand, G.A.; Raoult, D.; Dubourg, G. Antibiotic discovery: History, methods and perspectives. Int. J. Antimicrob. Agents 2019, 53, 371-382. [CrossRef] [PubMed]

2. Plüss-Suard, C.; Pannatier, A.; Kronenberg, A.; Muhlemann, K.; Zanetti, G. Hospital antibiotic consumption in Switzerland: Comparison of a multicultural country with Europe. J. Hosp. Infect. 2011, 79, 166-171. [CrossRef] [PubMed]

3. Van Boeckel, T.P.; Gandra, S.; Ashok, A.; Caudron, Q.; Grenfell, B.T.; Levin, S.A.; Laxminarayan, R. Global antibiotic consumption 2000 to 2010: An analysis of national pharmaceutical sales data. Lancet Infect. Dis. 2014, 14, 742-750. [CrossRef] 
4. Glinz, D.; Leon Reyes, S.; Saccilotto, R.; Widmer, A.F.; Zeller, A.; Bucher, H.C.; Hemkens, L.G. Quality of antibiotic prescribing of Swiss primary care physicians with high prescription rates: A nationwide survey. J. Antimicrob. Chemother. 2017, 72, 3205-3212. [CrossRef] [PubMed]

5. Roope, L.S.J.; Smith, R.D.; Pouwels, K.B.; Buchanan, J.; Abel, L.; Eibich, P.; Butler, C.C.; Tan, P.S.; Walker, A.S.; Robotham, J.V.; et al. The challenge of antimicrobial resistance: What economics can contribute. Science 2019, 364, eaau4679. [CrossRef] [PubMed]

6. Allcock, S.; Young, E.H.; Holmes, M.; Gurdasani, D.; Dougan, G.; Sandhu, M.S.; Solomon, L.; Torok, M.E. Antimicrobial resistance in human populations: Challenges and opportunities. Glob. Health Epidemiol. Genom. 2017, 2, e4. [CrossRef]

7. Durkin, M.J.; Hsueh, K.; Sallah, Y.H.; Feng, Q.; Jafarzadeh, S.R.; Munshi, K.D.; Lockhart, P.B.; Thornhill, M.H.; Henderson, R.R.; Fraser, V.J. An evaluation of dental antibiotic prescribing practices in the United States. J. Am. Dent. Assoc. 2017, 148, 878-886.e871. [CrossRef]

8. Rescala, B.; Rosalem, W., Jr.; Teles, R.P.; Fischer, R.G.; Haffajee, A.D.; Socransky, S.S.; Gustafsson, A.; Figueredo, C.M. Immunologic and microbiologic profiles of chronic and aggressive periodontitis subjects. J. Periodontol. 2010, 81, 1308-1316. [CrossRef]

9. Herbert, B.A.; Novince, C.M.; Kirkwood, K.L. Aggregatibacter actinomycetemcomitans, a potent immunoregulator of the periodontal host defense system and alveolar bone homeostasis. Mol. Oral. Microbiol. 2016, 31, $207-227$. [CrossRef]

10. Zenobia, C.; Hajishengallis, G. Porphyromonas gingivalis virulence factors involved in subversion of leukocytes and microbial dysbiosis. Virulence 2015, 6, 236-243. [CrossRef]

11. Keestra, J.A.; Grosjean, I.; Coucke, W.; Quirynen, M.; Teughels, W. Non-surgical periodontal therapy with systemic antibiotics in patients with untreated chronic periodontitis: A systematic review and meta-analysis. J. Periodontal. Res. 2015, 50, 294-314. [CrossRef] [PubMed]

12. Chatterjee, A.; Modarai, M.; Naylor, N.R.; Boyd, S.E.; Atun, R.; Barlow, J.; Holmes, A.H.; Johnson, A.; Robotham, J.V. Quantifying drivers of antibiotic resistance in humans: A systematic review. Lancet Infect. Dis. 2018, 18, e368-e378. [CrossRef]

13. Eick, S.; Schmitt, A.; Sachse, S.; Schmidt, K.H.; Pfister, W. In vitro antibacterial activity of fluoroquinolones against Porphyromonas gingivalis strains. J. Antimicrob. Chemother. 2004, 54, 553-556. [CrossRef] [PubMed]

14. Kulik, E.M.; Lenkeit, K.; Chenaux, S.; Meyer, J. Antimicrobial susceptibility of periodontopathogenic bacteria. J. Antimicrob. Chemother. 2008, 61, 1087-1091. [CrossRef] [PubMed]

15. Köhler, M.; Meyer, J.; Linder, M.; Lambrecht, J.T.; Filippi, A.; Kulik Kunz, E.M. Prescription of antibiotics in the dental practice: A survey of dentists in Switzerland. Schweiz. Monatsschr. Zahnmed. 2013, 123, 748-759.

16. Johnson, T.M.; Hawkes, J. Awareness of antibiotic prescribing and resistance in primary dental care. Prim. Dent. J. 2014, 3, 44-47. [CrossRef]

17. Veloo, A.C.; Seme, K.; Raangs, E.; Rurenga, P.; Singadji, Z.; Wekema-Mulder, G.; van Winkelhoff, A.J. Antibiotic susceptibility profiles of oral pathogens. Int. J. Antimicrob. Agents 2012, 40, 450-454. [CrossRef]

18. Dahlen, G.; Preus, H.R. Low antibiotic resistance among anaerobic Gram-negative bacteria in periodontitis 5 years following metronidazole therapy. Anaerobe 2017, 43, 94-98. [CrossRef]

19. Rams, T.E.; Degener, J.E.; van Winkelhoff, A.J. Antibiotic resistance in human chronic periodontitis microbiota. J. Periodontol. 2014, 85, 160-169. [CrossRef]

20. Xie, Y.; Chen, J.; He, J.; Miao, X.; Xu, M.; Wu, X.; Xu, B.; Yu, L.; Zhang, W. Antimicrobial resistance and prevalence of resistance genes of obligate anaerobes isolated from periodontal abscesses. J. Periodontol. 2014, 85, 327-334. [CrossRef]

21. Al-Ahmad, A.; Ameen, H.; Pelz, K.; Karygianni, L.; Wittmer, A.; Anderson, A.C.; Spitzmuller, B.; Hellwig, E. Antibiotic resistance and capacity for biofilm formation of different bacteria isolated from endodontic infections associated with root-filled teeth. J. Endod. 2014, 40, 223-230. [CrossRef]

22. Eick, S.; Seltmann, T.; Pfister, W. Efficacy of antibiotics to strains of periodontopathogenic bacteria within a single species biofilm-An in vitro study. J. Clin. Periodontol. 2004, 31, 376-383. [CrossRef]

23. Kulik Kunz, E.M.; Lenkeit, K.; Waltimo, T.; Weiger, R.; Walter, C. Combinatorial effects of amoxicillin and metronidazole on selected periodontal bacteria and whole plaque samples. Arch. Oral. Biol. 2014, 59, 608-615. [CrossRef] [PubMed] 
24. Brown, J.L.; Johnston, W.; Delaney, C.; Short, B.; Butcher, M.C.; Young, T.; Butcher, J.; Riggio, M.; Culshaw, S.; Ramage, G. Polymicrobial oral biofilm models: Simplifying the complex. J. Med. Microbiol. 2019, 68, 1573-1584. [CrossRef] [PubMed]

25. Eick, S.; Pfister, W. Efficacy of antibiotics against periodontopathogenic bacteria within epithelial cells: An in vitro study. J. Periodontol. 2004, 75, 1327-1334. [CrossRef] [PubMed]

26. Pitiriga, V.; Vrioni, G.; Saroglou, G.; Tsakris, A. The impact of antibiotic stewardship programs in combating quinolone resistance: A systematic review and recommendations for more efficient interventions. Adv. Ther. 2017, 34, 854-865. [CrossRef]

27. Eick, S.; Straube, A.; Guentsch, A.; Pfister, W.; Jentsch, H. Comparison of real-time polymerase chain reaction and DNA-strip technology in microbiological evaluation of periodontitis treatment. Diagn. Microbiol. Infect. Dis. 2011, 69, 12-20. [CrossRef]

28. Tran, C.M.; Tanaka, K.; Watanabe, K. PCR-based detection of resistance genes in anaerobic bacteria isolated from intra-abdominal infections. J. Infect. Chemother. 2013, 19, 279-290. [CrossRef]

29. EUCAST. Breakpoint Tables for Interpretation of MICs and Zone Diameters. v 9.0.1, 01.01.2019. Available online: http://www.eucast.org/clinical_breakpoints (accessed on 25 October 2019).

(C) 2019 by the authors. Licensee MDPI, Basel, Switzerland. This article is an open access article distributed under the terms and conditions of the Creative Commons Attribution (CC BY) license (http://creativecommons.org/licenses/by/4.0/). 